\title{
Study on Reinforcement and Seismic Performance of Cavity Walls' Housing
}

\author{
Jiangsu Province Rudong County Housing and Urban and Rural Construction Bureau Jiangsu Nantong 226400
}

\section{Cavity wall housing profile}

Cavity wall can be said that it's China's unique residential buildings, in the 20th century, 70 years ago, due to the larger housing gap in China, in accordance with the "more, fast, good, cheap" province principle, cavity wall of the form of housing was promoted. At the time to solve the fewer residents of the housing problem, almost all kinds of use of housing are used cavity wall structure. Ordinary brick structure with a wide range of materials, the construction process is simple and the advantages of low cost, cavity wall housing because of its own masonry, materials are more provincial, lighter weight, heat insulation, sound insulation performance. The disadvantages are the low vertical carrying capacity, the wall is easy to crack and the integrity is poor. From the Wenchuan earthquake statistics, masonry structure damage accounted for more than $80 \%$ of the total number of residents for their own use of cavity wall masonry form of a larger proportion.

Based on the shortcomings of the cavity wall, the important part of the wall needs to be made in solid, such as doors and windows, vertical and horizontal wall junction, the floor below the floor foot wall, floor 3 to 4 under the tiles and bear the concentrated load of the site ( such as a roof or beam). The cavity wall can be reinforced with reinforced concrete beams, reinforced tiles or beams. The larger space inside the building or 2 to 3 layers of the building, should be the whole circle of reinforced

brick ring beam.

\section{Study on Reinforcement of Cavity Wall}

2.1 Ring beam structure column is currently in practice the most used a class of reinforcement method. 1) In the 1990s, two kinds of reinforcement methods were tested on the seismic capacity of cavity wall houses. The results show that the reinforcement of the reinforced concrete beam can prevent the wall from cracking, but the improvement of the shear capacity of the wall is not more than $20 \%$. The main effect is to enhance the anti- degradation is slower than before reinforcement. Second, the steel mesh reinforced concrete mortar reinforcement cavity wall, research shows that the emphasis and thickness of the mortar directly affect the reinforcement effect. The synergistic effect of the mortar surface layer and the cavity wall improves the shear capacity. At the same time, the masonry (mainly the proportion of sleeping bricks) will affect the anti-seismic performance of the undeveloped cavity wall, but the effect on the reinforcement of the cavity wall has little effect; the reinforced wall not only significantly improves the seismic performance, while the damage before the harbinger played a warning role, changed the cavity wall brittle damage without signs of the shortcomings; ring beam structure column strip reinforcement effect than the scissors support form is more obvious. 2) The use of steel mesh cement mortar reinforcement crack wall, qualitative analysis of the role of steel mesh

\begin{abstract}
China's rural and urban construction is very different, rural construction houses generally use the form of masonry, including the main residential and other public buildings. In some of the more economically backward rural areas, housing basically self-built, almost impossible for formal design and construction quality is uneven. The earthquake capacity of these houses can be imagined, and "small earthquake disaster" is its main feature. In view of the large number of rural housing in the short term, it is impossible to dismantle all of these houses in almost undefended state, and let the residents stay away from such a dangerous room, which will be a relatively long asymptotic process, so the existing housing seismic reinforcement has become an urgent problem to be solved.
\end{abstract}

Key words: Empty bucket wall house; reinforcement; seismic performance

Published online: 15th July, 2017

in the reinforcement. The results show that the crack load and ultimate load of the composite wall are improved remarkably. 3) Considering the factors such as masonry, aspect ratio, vertical stress and mortar strength, 20 cavity walls were designed and 
studied. Through the actual verification, the initial crack load and the ultimate load of the inflated wall structure are improved by about $60 \%$, and the seismic performance is obviously improved. 4) Seismic analysis of single-layer transverse wall, double-wall and vertical wall windows with different mortar strength, aspect ratio and vertical compressive stress, and the cracked position of the wall after reinforcement. But the reinforcement of the steel mesh makes the wall transition from the shear failure to the bending failure. The damage of the wall of the double-wall is prone to damage: the damage of the wall of the vertical wall is greatly influenced by the aspect ratio. The particularity of the window wall, the reinforcement of the vertical and horizontal walls can be used to shear the seismic response analysis.

2.2 Composite fiber cloth reinforcement, the reinforcement form is more flexible. 1) On the different masonry, different ways to paste the carbon fiber cloth after the reinforcement of the cavity wall test. The results show that the anti-seismic performance of the cavity wall is better than that of the whole cavity wall. The anti-seismic performance of the cavity wall is the expected to be effective. 2) The analysis of different mortar strength, aspect ratio, different fiber types and pasting methods changed the failure mode after the composite fiber reinforced concrete, obviously improved the crack resistance and shear capacity.

\section{Countermeasure of Earth- quake on cavity wall housing}

3.1 To strengthen the original cavity wall of the house detection

Compared to some of the older empty cavity wall houses, because most have become dangerous. Especially for people's lives and the property has a certain degree of harm, so they need to strengthen the detection of these houses and in accordance with the actual test results on the actual situation for processing.

If it used for too long duration and its own usage functionality is very poor while the implementation of the reinforcement in the implementation of the cost is relatively high, it can be demolished; relative to some of a long time but no structural defects of housing, it can be implemented as a whole reinforcement or local maintenance, in order to strengthen the seismic performance of housing, which will extend the life of the house. In short, the need to build from the actual construction of the house and the application of the actual seismic performance and other aspects of its analysis, so that the use of relevant measures to continuously improve people's living standards, so as to effectively meet people's property security.

3.2 Regulate the rural building materials market, promote and promote new materials and new technologies

Relevant government departments need to continue to strengthen the improvement of the building materials market, and constantly strengthen the supervision and management of the village housing. And the need to live with the actual situation of the actual town, to strengthen the certification of building materials management. Continue to strengthen the quality of qualified materials and energy-saving materials, some illegal production suppliers to ban, which including do material management and continuously improve the new materials and new technologies for effective use. This work as a small town to promote the modernization of housing industry is an important task.

3.3 To strengthen the floor, additional construction measures

At East China and South of China, due to the relatively small earthquake and low magnitude, so in the construction of the earthquake requirements is not very high, and because the cost of the prefabricated floor is very low, so in these areas for the application of prefabricated floor is very common. In general, the stiffness of the prefabricated panel and the impermeability and shock resistance are not strong in the cast-in-place concrete, and each of the prefabricated panels in the construction if the length of the placement is too small, the lack of a certain pull between the plates, which will cause the floor to fall when the earthquakes are generated. Therefore, in order to enhance its seismic quality, prefabricated floor cover plate should be left with anchoring steel bars, and with other components to ensure adequate pull knot. Therefore, when the floor is a prefabricated floor hollow floor, in addition to the need to have enough pulling force, but also in the appropriate location for the addition of ring beam structure column, in order to enhance the overall performance of the building and seismic performance.

\section{Conclusion}

In short, in terms of seismic performance, the cavity wall housing is not better than a solid wall housing, and in the maintenance of the difficulty is also large, and the high cost, so the government needs to promote people to build less cavity wall house. The performance of a better solid wall to replace the cavity wall, in order to enhance the rural housing seismic capacity, so as to ensure people's property security.

\section{References}

[1] Liu Yibin. High Performance Composite Mortar Reinforcement Net Reinforcement Wall Structure Performance Research [D]. Hunan University, 2011.

[2] Lei Min. Study on Seismic Performance of Cavity Wall and HPFL Reinforced Cavity Wall [D]. Hunan University, 2013.

[3] Wang Hongyang. Village Masonry Building Seismic Construction Technology Research [D]. Harbin Institute of Technology, 2013. 